\title{
Knowledge, Attitude and Practice Towards Kangaroo Mother Care Among Postnatal Women in Ethiopia: Systematic Review and Meta-Analysis Author
}

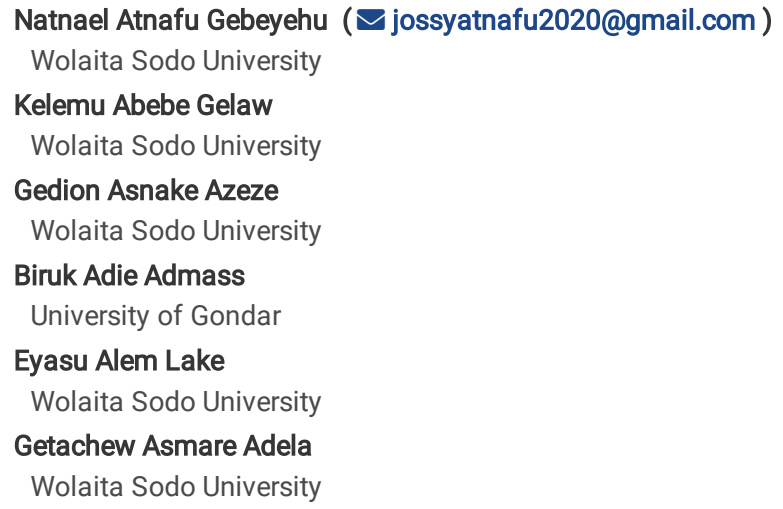




\section{Abstract}

Background: Kangaroo mother care could be a key procedure to decrease neonatal mortality and morbidity of preterm and low-birth-weight neonates. However, in Ethiopia, preterm birth and low-birth-weight neonatal death still exist. This study aimed to determine the pooled prevalence of knowledge, Attitude, and practice of kangaroo mother care among postnatal women in Ethiopia.

Methods: PubMed, Web of Science, Google Scholar, EMBASE, manual search, and Ethiopian University online library were searched. The data were extracted by using Microsoft excel and analyzed by STATA version 11 statistical software. The Publication bias was checked by funnel and more objectively through Egger's test and Begg's test with $\mathrm{P}<0.05$ considered being a potential publication for bias. $\mathrm{I}^{2}$ was used to check for the presence of heterogeneity of the studies. Overall estimated analysis was done. Subgroup analysis was done by region, study setting, publications, gestational age, birth weight, and the component of kangaroo care. Sensitivity analysis was conducted to see the effect of a single study on the pooled estimation.

Results: A total of 5 studies with 1,232 respondents for knowledge, five studies with 1,232 respondents for attitude, and 16 studies with 12,475 respondents for practice were used to estimate the pooled level of good knowledge, positive attitude, and poor practice of kangaroo mother care among postnatal women. The pooled estimate of good knowledge, positive attitude and poor practice of kangaroo mother care was found to be $64.62 \%\left(95 \% \mathrm{Cl}: 47.15 \%-82.09 \%\right.$; $\left.\right|^{2}=$ $97.8 \%), 61.55 \%\left(49.73-73.38 \% ;\left.\right|^{2}=94.8 \%\right)$ and $45.7 \%\left(95 \% \mathrm{Cl}: 37.297-54.092 \% ;\left.\right|^{2}=98.5 \%\right)$ respectively.

Conclusion: Findings showed significant gaps in kangaroo mother care-related knowledge, attitude, and practice compared with reported results of developed countries of the demographic health survey. Therefore, it is better to have periodic training and counseling on kangaroo mother care for postnatal women.

\section{Introduction}

Low birth weight and preterm birth are the major public health challenges within the neonatal period (1). During this period, $36 \%$ of passing happens promptly on the day of birth and $73 \%$ happen inside the primary week (2). More than $80 \%$ of neonatal passing happen in low birth weight neonates of which two-thirds of them are born preterm(3). Complications related to prematurity are the major cause of neonatal mortality(4). Around the world, low birth weight accounts for 25 million, and preterm birth accounts for 15 million of the $96 \%$ of were in developing countries $(5,6)$.In Ethiopia, systematic review and meta-analysis studies reported pooled prevalence of preterm birth(10.8\%), and low birth weight $(17.3 \%)(7,8)$.

The more prominent burden of preterm births and low birth weight needs more comprehensive interventional procedures for primary prevention such as Kangaroo Mother Care (9). As defined by the world health organization kangaroo mother care is an early, uninterrupted, and prolonged skin-to-skin contact between mother and until the baby doesn't remain in that position and the only breast nourishes child (10). Despite the recommendation of kangaroo mother care by the World Health Organization, Baby Friendly Initiative, United Nation International Children Emergency Fund, and American academy of pediatrics, the separation of a baby from the mother promptly after birth are remain a challenge (11-14).

Various works of literature also reported that kangaroo mother care is a cost-effective intervention in reducing mortality and morbidity of preterm infants (15) as well as affecting maternal health positively in low, middle, and high-income countries (16-22). The finding of the Cochrane review and a meta-analysis showed that kangaroo mother care diminished neonatal mortality $(17,23)$, sepsis $(17,23)$, hypothermia $(17,23)$, hypoglycemia(23), and length of stay $(17)$ compared to conventional care.

Several systematic review studies indicated that kangaroo mother care increased the success, initiation, and duration of breast milk (24-29), and improved maternal anxiety and stress( 30$)$, enhanced cognitive and motor development (31), diminished hospital readmission (32, 33) and lowered premature infant profile(34). Another study reported that Kangaroo mother care improves the growth of low birth weight and preterm infants (35-41).

In Ethiopia, kangaroo mother care was begun in 1996 at Black lion hospital. Since that point, the service has been expanded to other different health facilities and hospitals. As of late, the Federal Ministry of Health has integrated kangaroo mother care into National Strategy for Newborn and Child Survival, Health Sector Transformation Plan, and National Health Care Quality Strategy focused on reaching $80 \%$ of preterm babies to get kangaroo mother care, but the initiation remains low (42-44). In addition, in Ethiopia, the neonatal mortality rate is 30 per 1000 live births means that the problem remains high (45). By the end of 2030, Ethiopia focused on lowering the neonatal mortality rate to 12 deaths per 1000 live births (46). To attain this target, Kangaroo mother care plays a significant part in anticipating neonatal hypothermia (11)

The worldwide prevalence of kangaroo mother care practice ranged from $1 \%$ in Tanzania (47) to $96 \%$ in Denmark (48). In Ethiopia, the findings of knowledge of kangaroo mother care ranged from $35.5-82.53 \%(49-53)$, attitude ranged from $50-82.53 \%(49-53)$ and practice ranged from $23-83 \%$ across the nation (49-64). With these variations of reports, there is no overall estimate of representative national data in Ethiopia. Therefore, this study aimed at determining the pooled prevalence of knowledge, Attitude, and practice of kangaroo mother care among postnatal women in Ethiopia, and that will provide fundamental data for policymakers, clinicians, and concerned stakeholders to enhance an appropriate strategy and intervention in the control and management of kangaroo mother care.

\section{Methods}

\section{Searching strategy and information sources}

We searched on PubMed, Web of Science, Google Scholar, EMBASE, manual search, and Ethiopian (Addis Ababa)University Online repository library databases to get the available studies using the following search terms and phrases: "Knowledge of kangaroo mother care", "attitude of kangaroo mother 
care", "kangaroo mother care", "low birth weight neonate", "preterm neonate", "newborn care practice”, "kangaroo mother", "skin to skin care practice", "skin to skincare", and "kangaroo mother care method". All methods were performed in accordance with the relevant guidelines and regulations.

The search strategy in PubMed was:(((((((Knowledge [tw]) OR "Knowledge"[Mesh Terms]) AND (Attitude[tw] OR perception [tw])) OR "Attitude " [Mesh Terms]) AND Practice [tw]) OR "Practice" [Mesh Terms]) AND (Kangaroo mother care[tw] OR low birth weight neonate[tw]OR preterm neonate[tw] OR newborn care practice[tw])) OR ("Kangaroo mother care " [Mesh Terms] OR "Kangaroo mother " [Mesh Terms] OR "skin to skin care practice" [Mesh Terms] OR "skin to skin care"[Mesh Terms] OR" kangaroo mother care method" [Mesh Terms])) AND Ethiopia

The research team used Preferred Reporting Items for Systematic Reviews and Meta-Analysis (PRISMA) guidelines to report findings (65).

\section{Operational definitions}

\section{Knowledge}

Those study participants who were responded $\geq 50 \%$ of knowledge-related questions were considered as having good knowledge and those who responded less than $50 \%$ were considered as poor knowledge (49).

\section{Attitude}

Those respondents who answered $\geq 50 \%$ mean value on attitude-related questions were considered as positive attitude whereas those respondents who answered below the mean score of attitude-related questions were considered as having a negative attitude.

\section{Practice}

Those study participants who responded $\geq 50 \%$ of practice-related questions were categorized as having a good practice whereas those respondents who answered $<50 \%$ of questions were considered as having poor practice.

\section{Eligibility criteria}

Those articles included in this systematic review and meta-analysis if 1 . Study type: All observational studies reporting the prevalence of knowledge, attitude, and practice of kangaroo mother care 2. Population: Studies done among postnatal women 3. Language: English 4. Place of study: Ethiopia 5.full text was available during searching.

Those articles excluded in this systematic review and meta-analysis if: 1. unrelated research works 2 . The studies with inadequate information 3. Duplicate sources 4. Qualitative studies on episiotomy 5. Interventional studies; case reports 6 . Articles that their full text was not available: an attempt was made to contact the corresponding author

\section{Study selection and Data extraction}

Two independent authors selected the candidate articles for the study. They exported to the reference manager software; endnote software to remove duplicate studies. They independently screened the title and abstract (NA, KA, and EA). The disagreement was resolved within a team through discussions by a third author. Data were extracted using a standardized data extraction format prepared in Microsoft Excel by four independent authors (NA, GA, BA and GA). Any ideal difference that happened during extraction was also solved through discussion by the fourth author. The name of the first author, year of publication, study region, study setting, the prevalence of knowledge of kangaroo mother care, the attitude of kangaroo mother care, the practice of kangaroo mother care, sample size, gestational age, type of kangaroo mother care and birth weight were collected.

\section{Quality assessment}

The two independent authors appraised the standard of the studies. The Joanna Briggs Institute (JBI) quality appraisal checklist was used (31). When there is any disagreement all the two authors discussed and resolved it. The critical analysis checklist has 8 parameters with yes, no, unclear, and not an applicable option. The parameter involves the subsequent questions: (1) Where were the criteria for inclusion in the sample clearly defined?, (2)Were the study subjects and therefore the setting described in detail?, (3) Was the exposure measured the result validly and reliably?, (4) Were main objective, standard criteria used for measurement of the event?, (5) Were confounding factors identified?, (6) Were strategies to affect confounding factors stated?, (7 Were the results measured truly and dependably?, and (8) Was suitable statistical analysis used?. Studies were considered low risk when they scored $50 \%$ and above of the quality assessment indicators.

\section{Statistical analysis}

After data extraction was done using Microsoft Excel, the analysis was conducted by using STATA version 14 statistical software. Publication bias was checked by funnel plot and more objectively through Begg and Egger's regression tests, with $\mathrm{P}<0.05$ considered to indicate potential publication bias. A trim and fill analysis was done to see the effect of publication bias. It adds studies to form the distribution symmetrical. The presence of heterogeneity betweenstudy was checked by using Cochrane Q statistic. This heterogeneity between study was quantified using $\mathrm{I}^{2}$, in which a value of $0,25,50$, and $75 \%$ represented no, low, medium, and in-creased heterogeneity, respectively. A forest plot was used to assess the presence of heterogeneity visually. Since a high level of heterogeneity was found, a random-effect model was used for analysis to estimate the overall prevalence of episiotomy practice. Subgroup analysis was done by study setting, region, gestational age, birth weight, and type of kangaroo care practice. A sensitivity analysis was done to see the effect of a single study on the overall prevalence of the meta-analysis estimate. The finding of the study was presented in the form of text, tables, and figures.

\section{Result}




\section{Selection of included studies}

There were 273 research articles retrieved using electronic search. Of these articles, 117 were expelled since duplication and 95 studies were excluded after reviewing their titles and abstracts. At the qualification stage, 61 articles were completely gotten to and evaluated for the capability. Finally, 16 studies (49-64) with 12,475 participants were included in this systematic review and meta-analysis. All studies were cross-sectional studies and reported the prevalence of knowledge, attitude, and practice of kangaroo mother care (Fig. 1)

\section{Description of included studies}

Out of 273 articles retrieved at first, sixteen articles met the eligibility criteria and were included in the final meta-analysis as reported by Fig. 1 . The author's name, publication year, study design, sample size, study region, study setting, response rate, birth weight, kangaroo mother care type, gestational age, the prevalence of knowledge, attitude, and practice of kangaroo mother care had listed out in the below Table1.

Four studies were found in Addis Ababa (50,54-56), three in Southern Nations Nationalities and Peoples Region(49, 51, 61), two at the national level(57, 59), one in Amhara (60), two in Tigray $(58,64)$, one in Somali(62), one in Harar and Dire Dawa (52), one in Harar(53), and one in Addis Ababa, Amhara, Oromia and Benishanguel Gumize (63). All were cross-sectional studies. Of the total of sixteen studies, twelve were institutional-based studies, but four were communitybased studies. The earliest study was conducted in 2014 and the latest was conducted in 2021. The sample size ranged from 86 to 7488 . The prevalence of knowledge, attitude, and practice of kangaroo mother care ranged were ranged from $35.5 \%-82.53 \%, 50 \%-82.53 \%$, and $28 \%-83 \%$ respectively. The response rate ranged from 92 percent to 100 percent. Eight studies were done with any gestational age (preterm, term, and post-term) infants whereas the remaining was done only on preterm infants.

All selected studies were evaluated for methodological quality based on The Joanna Briggs Institute (JBI) cross-sectional quality assessment method. All sixteen studies were included based on the quality assessment criteria. All of these studies had reported a low risk (Table 1). 
Table 1

Descriptions of the studies used in the systematic review and meta-analysis for the knowledge, attitude, and practice of kangaroo mother care among postna in Ethiopia.

\begin{tabular}{|c|c|c|c|c|c|c|c|c|c|c|c|}
\hline Author/year & $\begin{array}{l}\text { Study } \\
\text { region }\end{array}$ & $\begin{array}{l}\text { Study } \\
\text { Setting }\end{array}$ & $\begin{array}{l}\text { Study } \\
\text { design }\end{array}$ & $\begin{array}{l}\text { Sample } \\
\text { Size }\end{array}$ & $\begin{array}{l}\text { Response } \\
\text { rate }\end{array}$ & $\begin{array}{l}\text { Good } \\
\text { knowledge }\end{array}$ & $\begin{array}{l}\text { Good } \\
\text { attitude }\end{array}$ & $\begin{array}{l}\text { Good } \\
\text { practice }\end{array}$ & GA & $\begin{array}{l}\text { KMC } \\
\text { Type }\end{array}$ & $\begin{array}{l}\text { Weight } \\
\text { (KG) }\end{array}$ \\
\hline Mose et.al/2021 & SNNP & $\begin{array}{l}\text { Health } \\
\text { center }\end{array}$ & $\begin{array}{l}\text { Cross- } \\
\text { sectional }\end{array}$ & 382 & 100 & 35.5 & 50 & 35.3 & $\begin{array}{l}\text { Any } \\
\text { age }\end{array}$ & $\begin{array}{l}\text { SSC } \\
+\mathrm{BF}\end{array}$ & $\begin{array}{l}\text { Any } \\
\text { weight }\end{array}$ \\
\hline Gebre et.al/2018 & Somali & Community & $\begin{array}{l}\text { Cross- } \\
\text { sectional }\end{array}$ & 829 & 98.3 & $\begin{array}{l}\text { Not } \\
\text { reported }\end{array}$ & $\begin{array}{l}\text { Not } \\
\text { reported }\end{array}$ & 23 & $\begin{array}{l}\text { Any } \\
\text { age }\end{array}$ & $\begin{array}{l}\text { SSC } \\
+\mathrm{BF}\end{array}$ & $\begin{array}{l}\text { Any } \\
\text { weight }\end{array}$ \\
\hline Roba AA/2018 & $\begin{array}{l}\text { Harar \& } \\
\text { DireDawa }\end{array}$ & Hospital & $\begin{array}{l}\text { Cross- } \\
\text { sectional }\end{array}$ & 349 & 100 & 69.91 & 63.33 & 54.51 & $\begin{array}{l}\text { Any } \\
\text { age }\end{array}$ & $\begin{array}{l}\text { SCC } \\
\text { only }\end{array}$ & $<.5 \mathrm{~kg}$ \\
\hline Jamie ,A.H /2020 & Harar & Hospital & $\begin{array}{l}\text { Cross- } \\
\text { sectional }\end{array}$ & 166 & 100 & 82.53 & 82.53 & 32.13 & $\begin{array}{l}\text { Any } \\
\text { age }\end{array}$ & $\begin{array}{l}\text { SSC } \\
\text { only }\end{array}$ & $\begin{array}{l}2.5 \mathrm{~kg} \\
\mathbf{2}\end{array}$ \\
\hline $\begin{array}{l}\text { Alelign, } \\
\text { Zewuditu/unpublished }\end{array}$ & $\begin{array}{l}\text { Addis } \\
\text { Ababa }\end{array}$ & Hospital & $\begin{array}{l}\text { Cross- } \\
\text { sectional }\end{array}$ & 249 & 100 & 69.1 & 54.22 & 43 & Preterm & $\begin{array}{l}\text { SSC } \\
+\mathrm{BF}\end{array}$ & $<1.5 \mathrm{~kg}$ \\
\hline Bedaso et.al/2019 & $\begin{array}{l}\text { Amhara, } \\
\text { Addis } \\
\text { Ababa, } \\
\text { Oromia }\end{array}$ & Hospital & $\begin{array}{l}\text { Cross- } \\
\text { sectional }\end{array}$ & 384 & 100 & $\begin{array}{l}\text { Not } \\
\text { reported }\end{array}$ & $\begin{array}{l}\text { Not } \\
\text { Reported }\end{array}$ & 40.1 & $\begin{array}{l}\text { Any } \\
\text { age }\end{array}$ & SSC & $\begin{array}{l}\text { Any } \\
\text { weight }\end{array}$ \\
\hline Getinet et.al/2019 & SNNP & Hospital & $\begin{array}{l}\text { Cross- } \\
\text { sectional }\end{array}$ & 86 & 92 & 68.6 & 57 & 61.6 & Preterm & $\begin{array}{l}\text { SSC } \\
\text { only }\end{array}$ & <. $2.5 \mathrm{~kg}$ \\
\hline $\begin{array}{l}\text { Dawit, Aster } \\
\text { /unpublished }\end{array}$ & $\begin{array}{l}\text { Addis } \\
\text { Ababa }\end{array}$ & Hospital & $\begin{array}{l}\text { Cross- } \\
\text { sectional }\end{array}$ & 297 & 100 & $\begin{array}{l}\text { Not } \\
\text { reported }\end{array}$ & $\begin{array}{l}\text { Not } \\
\text { reported }\end{array}$ & 71 & Preterm & $\begin{array}{l}\text { SSC } \\
+\mathrm{BF}\end{array}$ & $<1.5$ \\
\hline Dabere et.al/2020 & National & Community & $\begin{array}{l}\text { Cross- } \\
\text { sectional }\end{array}$ & 7488 & $\begin{array}{l}\text { Not } \\
\text { reported }\end{array}$ & $\begin{array}{l}\text { Not } \\
\text { reported }\end{array}$ & $\begin{array}{l}\text { Not } \\
\text { reported }\end{array}$ & 24.3 & $\begin{array}{l}\text { Any } \\
\text { age }\end{array}$ & $\begin{array}{l}\text { SSC } \\
\text { only }\end{array}$ & $\begin{array}{l}\text { Any } \\
\text { weight }\end{array}$ \\
\hline $\begin{array}{l}\text { Ebrahim yesuf } \\
\text { et.al/2018 }\end{array}$ & SNNP & Community & $\begin{array}{l}\text { Cross- } \\
\text { sectional }\end{array}$ & 215 & 100 & $\begin{array}{l}\text { Not } \\
\text { reported }\end{array}$ & $\begin{array}{l}\text { Not } \\
\text { reported }\end{array}$ & 41.9 & Preterm & $\begin{array}{l}\text { SSC } \\
\text { only }\end{array}$ & <.5kg \\
\hline M.W,Ayele et.al/2021 & Amhara & Community & $\begin{array}{l}\text { Cross- } \\
\text { sectional }\end{array}$ & 190 & 97 & $\begin{array}{l}\text { Not } \\
\text { reported }\end{array}$ & $\begin{array}{l}\text { Not } \\
\text { reported }\end{array}$ & 46.8 & $\begin{array}{l}\text { Any } \\
\text { age }\end{array}$ & $\begin{array}{l}\text { SSC } \\
\text { only }\end{array}$ & $<.5 \mathrm{~kg}$ \\
\hline $\begin{array}{l}\text { Haftey Gebremedihn } \\
\text { et,al / unpublished }\end{array}$ & Tigray & Hospital & $\begin{array}{l}\text { Cross- } \\
\text { sectional }\end{array}$ & 397 & 96.6 & $\begin{array}{l}\text { Not } \\
\text { reported }\end{array}$ & $\begin{array}{l}\text { Not } \\
\text { reported }\end{array}$ & 54.4 & $\begin{array}{l}\text { Any } \\
\text { age }\end{array}$ & $\begin{array}{l}\text { SSC } \\
\text { only }\end{array}$ & $<$ \\
\hline $\begin{array}{l}\text { Lakew W. and } \\
\text { B.Worku/2014 }\end{array}$ & $\begin{array}{l}\text { Addis } \\
\text { Ababa }\end{array}$ & Hospital & $\begin{array}{l}\text { Cross- } \\
\text { sectional }\end{array}$ & 110 & $\begin{array}{l}\text { Not } \\
\text { reported }\end{array}$ & $\begin{array}{l}\text { Not } \\
\text { reported }\end{array}$ & $\begin{array}{l}\text { Not } \\
\text { reported }\end{array}$ & 83 & Preterm & $\begin{array}{l}\text { SSC } \\
\text { only }\end{array}$ & $<1.5 \mathrm{~kg}$ \\
\hline Weldeargay et.al/2019 & National & Hospital & $\begin{array}{l}\text { Cross- } \\
\text { sectional }\end{array}$ & 768 & $\begin{array}{l}\text { Not } \\
\text { reported }\end{array}$ & $\begin{array}{l}\text { Not } \\
\text { reported }\end{array}$ & $\begin{array}{l}\text { Not } \\
\text { reported }\end{array}$ & 46.4 & Preterm & $\begin{array}{l}\text { SSC } \\
\text { only }\end{array}$ & $<1.5 \mathrm{~kg}$ \\
\hline Demissie et.al/2018 & $\begin{array}{l}\text { Addis } \\
\text { Ababa }\end{array}$ & Hospital & $\begin{array}{l}\text { Cross- } \\
\text { sectional }\end{array}$ & 356 & 100 & $\begin{array}{l}\text { Not } \\
\text { reported }\end{array}$ & $\begin{array}{l}\text { Not } \\
\text { reported }\end{array}$ & 47.2 & Preterm & $\begin{array}{l}\text { SSC } \\
+\mathrm{BF}\end{array}$ & $<1.5 \mathrm{~kg}$ \\
\hline Emishaw et.al/ & Tigray & Hospital & $\begin{array}{l}\text { Cross- } \\
\text { sectional }\end{array}$ & 109 & $\begin{array}{l}\text { Not } \\
\text { reported }\end{array}$ & $\begin{array}{l}\text { Not } \\
\text { reported }\end{array}$ & $\begin{array}{l}\text { Not } \\
\text { reporter }\end{array}$ & 28.12 & Preterm & $\begin{array}{l}\text { SSC } \\
\text { only }\end{array}$ & $\begin{array}{l}<.5 \mathrm{~kg} \\
\end{array}$ \\
\hline
\end{tabular}

\section{Level of Knowledge, Attitude, and Practice towards kangaroo mother care}

The pooled prevalence of knowledge, practice, and attitude towards kangaroo mother care in Ethiopia is presented by the forest plot (Figs. 2-4). By using the random-effect model, the pooled level of good knowledge was found in $64.62 \%\left(95 \% \mathrm{Cl}: 47.15 \%-82.09 \% ; \mathrm{I}^{2}=97.8 \%\right)$. The overall estimated positive attitude towards kangaroo mother care was found in $61.55 \%\left(49.73-73.38 \% ; I^{2}=94.8 \%\right)$. The pooled estimate of poor practice towards kangaroo mother care among postnatal women was found in $45.7 \%$ (95\%Cl: $\left.37.297-54.092 \% ; I^{2}=98.5 \%\right)$ (Fig. 2).

\section{Leave out-one sensitivity analysis}


A leave-out-one sensitivity analysis was done to detect the effect of each study on the overall all prevalence of good level of knowledge, positive level of attitude, and poor level of practice of kangaroo mother care of postnatal women by excluding each study step by step. The result showed that the excluded study brings significant change to the overall prevalence of a good level of knowledge, positive attitude, and poor practice. In the sensitivity analysis, both Jamie, A H. and Mose et.al had shown an impact on the pooled level of good knowledge and positive attitude whereas Lakew B. and B.Worku and Gebre et.al had an impact on the level of poor practice towards kangaroo mother care (Table 2).

Table 2

A Leave -out-one sensitivity analysis for knowledge, attitude, and practice of kangaroo mother care among postnatal women in Ethiopia

\begin{tabular}{|c|c|c|}
\hline \multicolumn{3}{|l|}{ Knowledge related articles } \\
\hline Study omitted & Pooled estimate & $95 \% \mathrm{Cl}$ \\
\hline Mose et.al & 72.22 & $64.92-79.53$ \\
\hline Roba AA et.al. & 63.31 & $40.30-86.32$ \\
\hline Jamie ,A.H & 60.11 & $41.44-78.77$ \\
\hline Zewuditu Alelign & 64.02 & $41.59-86.45$ \\
\hline Getinet et.al & 63.67 & $43.23-84.12$ \\
\hline \multicolumn{3}{|l|}{ Attitude related articles } \\
\hline Study omitted & Pooled estimate & $95 \% \mathrm{Cl}$ \\
\hline Mose et.al & 64.48 & $51.46-77.50$ \\
\hline Roba AA et.al. & 61.07 & $44.97-77.17$ \\
\hline Jamie ,A.H. & 56.17 & $49.59-62.76$ \\
\hline Alelign,zewuditu & 63.39 & $48.82-77.96$ \\
\hline Getinet et.al & 62.58 & $48.82-76.33$ \\
\hline \multicolumn{3}{|l|}{ Practice related articles } \\
\hline Study omitted & Pooled estimate & $95 \% \mathrm{Cl}$ \\
\hline Mose.et.al & 46.40 & $37.44-55.36$ \\
\hline Roba AA et.al & 45.10 & $36.52-53.68$ \\
\hline M.W. Ayele et.al & 45.62 & $36.90-54.35$ \\
\hline Getinet et.al & 44.70 & $36.12-53.28$ \\
\hline Gebere et.al & 47.26 & $37.83-56.69$ \\
\hline Dawit, Aster & 43.96 & $36.11-51.82$ \\
\hline Bedaso et.al & 46.08 & $37.17-54.98$ \\
\hline Dabere et.al & 47.16 & $38.94-55.38$ \\
\hline Demissie et.al & 45.60 & $36.83-54.36$ \\
\hline Ebrahim Yesuf & 45.95 & $37.17-54.73$ \\
\hline Emishaw et.al & 46.83 & $38.07-55.59$ \\
\hline Jamie,A.H. & 46.59 & $37.79-55.40$ \\
\hline Zewditu Alelign & 45.88 & $37.09-54.67$ \\
\hline Tesfaye Geberemedihn & 45.10 & $36.54-53.67$ \\
\hline Weldearagay et.al & 45.65 & $36.75-54.55$ \\
\hline Lakew. W and B. Worku & 43.22 & $35.37-51.07$ \\
\hline
\end{tabular}

\section{Subgroup analysis}

The subgroup analysis based on kangaroo mother care type showed that the level of good knowledge was found $74 \%$ in only skin-to-skin contact and $51.2 \%$ in skin-to-skin contact with exclusive breastfeeding practice. The level of positive attitude towards kangaroo mother care type was found to be $67.98 \%$ in skinto-skin contact only and $51.85 \%$ in both skin-to-skin contacts with exclusive breastfeeding practice. In this subgroup analysis, the level of poor practice was done by study region, study setting, publication, type of kangaroo mother care, gestational age, and birth weight. The pooled level of poor kangaroo mother care practice by region was $60.99 \%$ in Addis Ababa, and $39.92 \%$ in another region (where a single study was done in single region/multiple regions). In the 
case of kangaroo mother care type, the prevalence of poor practice was found in $46.57 \%$ in only skin-to-skin contact practice and $43.84 \%$ in the skin-to-skin contact with exclusive breastfeeding. Regarding gestational age, the level of poor practice of kangaroo mother care was found to be $52.77 \%$ in the preterm neonate and $38.68 \%$ in any gestational age. The level of poor practice towards birth weight was $57.37 \%$ in birth weight less than $1.5 \mathrm{Kg}$, and $30.27 \%$ at any weight (Table 3).

Table 3

The overall estimated level of Good Knowledge, Positive Attitude, and poor practice towards kangaroo mother care in Ethiopia, $95 \% \mathrm{Cl}$ and heterogeneity estimate with a p-value for sub-group analysis

\begin{tabular}{|c|c|c|c|}
\hline \multicolumn{4}{|l|}{ Knowledge related articles } \\
\hline Variable & Characteristics & Pooled level of good knowledge $95 \%(\mathrm{Cl})$ & $I^{2}(p-v a l u e)$ \\
\hline \multirow[t]{2}{*}{ Kangaroo mother care type } & SSC only & $74 \%(64.744-83.236)$ & $83.1 \%(0.003)$ \\
\hline & $\mathrm{SSC}+\mathrm{BF}$ & $51.2 \%(19.991-82.318)$ & $98.4 \%(0.000)$ \\
\hline \multicolumn{4}{|l|}{ Attitude related articles } \\
\hline Variable & Characteristics & Pooled level of positive Attitude $95 \%(\mathrm{Cl})$ & $\mathrm{I}^{2}$ (p-value) \\
\hline \multirow[t]{2}{*}{ Kangaroo mother care type } & SSC only & $67.98 \%(52.968-82.997)$ & $93.5 \%(0.000)$ \\
\hline & $\mathrm{SSC}+\mathrm{BF}$ & $51.85 \%(47.958-55.749)$ & $0.0 \%(0.335)$ \\
\hline \multicolumn{4}{|l|}{ Practice related articles } \\
\hline Variables & Characteristics & Pooled level of poor practice $95 \%(\mathrm{Cl})$ & $\mathrm{I}^{2}$ (p-value) \\
\hline \multirow[t]{2}{*}{ Study setting } & Community & $33.067 \%(25.397-40.738)$ & $95.4 \%(0.000)$ \\
\hline & Institutional & $49.697 \%(41.801-57.594)$ & $95.9 \%(0.000)$ \\
\hline \multirow[t]{5}{*}{ Region } & Addis Ababa & $60.992 \%(43.326-78.658)$ & $97.3 \%(0.000)$ \\
\hline & SNNP & $45.505 \%(32.660-58.349)$ & $90.4 \%(0.000)$ \\
\hline & Tigray & $45.694 \%(37.297-54.092)$ & $96.4 \%(0.002)$ \\
\hline & Other & $39.228 \%(26.286-52.170)$ & $97 \%(0.002)$ \\
\hline & Nationwide & $35.282 \%(13.625-56.939)$ & $99.3 \%(0.001)$ \\
\hline \multirow[t]{2}{*}{ Publication } & Published & $43.217 \%(34.943-51.492)$ & $98.2 \%(0.000)$ \\
\hline & Unpublished & $56.200 \%(40.808-71.591)$ & $95.9 \%(0.000)$ \\
\hline \multirow[t]{2}{*}{ Kangaroo mother care type } & SSC only & $46.572 \%(35.565-57.579)$ & $98.6 \%(0.000)$ \\
\hline & $S S C+B F$ & $43.844 \%(26.763-60.925)$ & $98.6 \%(0.000)$ \\
\hline \multirow[t]{2}{*}{ Gestational age } & Preterm & $52.774 \%(41.867-63.681)$ & $96.3 \%(0.000)$ \\
\hline & Any age & $38.675 \%(29.920-47.429)$ & $97.9 \%(0.000)$ \\
\hline \multirow[t]{3}{*}{ Birth weight } & $<1.5 \mathrm{~kg}$ & $57.372 \%(46.223-68.522)$ & $96.5 \%(0.000)$ \\
\hline & $1.5-2.5 \mathrm{~kg}$ & $44.080 \%(34.683-53.478)$ & $90.3 \%(0.000)$ \\
\hline & Any weight & $30.274 \%(23.871-36.677)$ & $94.8 \%(0.000)$ \\
\hline
\end{tabular}

\section{Publication bias}

The presence of publication bias was checked by using funnel plot visualization and Egger test and Begg's regression test at p-value < 0.05 . Egger test and Begg test showed that there was no statistical evidence of publication bias for a good level of knowledge $(p=0.577$ and 0.240$)$ respectively (Fig. 5). There was also no statistical evidence of publication bias for a positive attitude with the Egger test $(p=0.928)$ and Begg test $(p=0.624)$ (Fig. 6$)$. The results of Begg's test $(P=0.000)$ and Egger's test $(p=0.000)$ showed the presence of publication bias for the level of poor practice of kangaroo mother care. In addition, asymmetric distribution was visualized in the funnel plot (Fig. 7). Subsequently, trim and fill analysis was done and indicated the presence of seven unpublished studies (Fig. 8). The counter-enhanced funnel plot was also done and the missing studies were in the areas of higher statically significance suggested that the cause of asymmetry was due to factors other than publication bias such as variables in the study (Fig. 9).

\section{Discussion}

Kangaroo mother care was first introduced in Ethiopia in 1996 at Black lion hospital. Since then, kangaroo mother care services have been expanded to other hospitals and health facilities at all levels. Nowadays, it has been issued in a series of policy documents by the Federal Ministry of Health, the Newborn and Child Survival Strategy 2015-2020, the Health Sector Transformation Plan, and the National Healthcare Quality Strategy. Despite the emphasis that the government has put to reduce neonatal mortality by using evidence-based strategies such as kangaroo mother care, Ethiopia is one of the sub-Saharan African countries with the most neonatal loss. 
Because of the inadequate available literature, we conducted this systematic review and meta-analysis to understand better the Knowledge, attitude and practice among women who gave birth in Ethiopia. We included all available studies using a variety of electronic search engines and were also able to undertake a sub-group analysis assessing the proportion of knowledge attitude and practice by study setting, study region, gestational age, component of kangaroo mother care, birth weight, and publications.

The finding of this study showed that the pooled prevalence of good knowledge of kangaroo mother care was $64.62 \%$. This is lower than a result of a national study done in America (75\%) among Nurses working in intensive care (66). The inconsistency can be due to the existing socio-economic, health system infrastructure, study population variation, and methodological differences including study design across the studies. The sub-group analysis based on components of kangaroo mother care showed that participants were more knowledgeable on skin-to-skin contact only than both skin-to-skin contact and exclusive breastfeeding. This finding is not surprising because exclusive breastfeeding was given attention lately.

More than sixty percent of women who gave birth in Ethiopia had a positive attitude towards kangaroo mother care (61.5\%). This finding is consistent with a national done in America that yielded that over $60 \%$ of respondents had a good perception of kangaroo mother care (66). The sub-group analysis revealed that participants had a positive attitude for skin-to-skin contact only than both skin-to-skin contact and exclusive breast feeding which might be due to the lack of long-term exposure of exclusive breast feeding.

The pooled level of poor practice of kangaroo mother care was $45.7 \%$. This was relatively lower than with the findings of national surveys done in Denmark, America, Taiwan, and Canada, which yielded $96 \%, 82 \%, 64 \%$, and $50 \%$ respectively $(66-69)$. The conceivable clarification to the disparity was due to methodological differences such as study design and socio-cultural difference across the countries which intern affects the practice of kangaroo mother care In addition to this, Ethiopia is one of the low-income countries with poor economic status as well as with poor maternal and child health coverage with a low level of skilled delivery. The sub-group analysis showed that poor practice was observed in the community-based study, skin-to-skin contact and exclusive breastfeeding, any weight, and any gestational age whereas a high level of practice was reported in Addis Ababa. This indicated to us the significance of kangaroo mother care for very low birth weight, low birth weight, and preterm neonates as well as the need to enhance the procedure at the community level. Regarding with region, Addis Ababa had a big share of kangaroo mother care practice which might be due to the adaptation of the procedure both by client and health providers for a long time since its' introduction at the first time at Black lion hospital, a senior and earliest specialized hospital, located in Addis Ababa, Ethiopia.

In this study, we used a random-effect model to manage a significant variation that resulted in between-study heterogeneity. We assessed leave one-out-one sensitivity analysis, and the result showed that every single study had a significant impact on the pooled good level of knowledge, positive attitude, and poor level practice of kangaroo mother care. We also assessed the possible source of variability by sub-group analysis using study setting, region, publications, gestational age, birth weight, and components of kangaroo mother care. The high heterogeneity might be due to differences in the sample population between studies, paper quality, socio-cultural, ethnic, and regional difference claims this variation.

\section{Conclusion}

In conclusion, this systematic review and meta-analysis reported that there was a significant gap in knowledge, attitude, and practice of kangaroo mother care among women in Ethiopia. Besides, the pooled prevalence of knowledge, attitude, and practice differed by study setting, region, publications, gestational age, birth weight, and components of kangaroo mother care. The information generated from this finding has to be used for the provision of accurate and up-todate training and education of kangaroo mother care. Therefore, it is better to have periodic training for postnatal women about kangaroo mother care and expand service dimensions across the community level. In Addition to this, further research is required to determine the knowledge, attitude, and practice of kangaroo mother care in the country and obtaining relevant information on why the gap of knowledge, attitude, and practice of kangaroo mother care still remains as a challenge.

\section{Strength and limitation of the study}

The strength of the study including the use of a comprehensive electronic search strategy through the variety of datasets to determine the overall level of knowledge, attitude, and practice of kangaroo mother care, the use of JBI-MAStARI appraisal, and the accessing of grey literature's. This study also had some limitations. These were the absence of a standard definition of good knowledge, positive attitude, and poor practice of kangaroo mother care to operationalize by the research team and might be researched bias on a cut of point. The absence of a similar previous study makes it is very difficult to compare the findings of this study. The study had included the whole regions of the country, but Afar and Gambela.

\section{Declarations}

\section{Acknowledgments}

Not applicable.

\section{Authors' contributions}

NA conceived and designed the study. NA and KA established the search strategy.NA, GA, and EA did the statistical analysis of this research. NA, KA, GA, BA, $\mathrm{GA}$, and EA wrote the review. All the authors read the manuscript before they have given the final approval for publication. 
NA: School of Midwifery, College of Medicine and Health Sciences, Wolaita Sodo University, Sodo, Ethiopia.

KA: School of Midwifery, College of Medicine and Health Sciences, Wolaita Sodo University, Sodo, Ethiopia

GA: School of Midwifery, College of Health Science and Medicine, Wolaita Sodo University, Wolaita Sodo, Ethiopia

BA: Department of Anesthesia, College of Health Science and Medicine, University of Gondar, Gondar, Ethiopia

EA: School of Nursing, College of Health Science and Medicine, Wolaita Sodo University, Wolaita Sodo, Ethiopia

GA:School of Public Health, College of Health Science and Medicine, Wolaita Sodo University, Wolaita Sodo, Ethiopia

\section{Funding}

Not applicable.

\section{Availability of data and materials}

All data generated or analyzed during this study are included in this published article.

\section{Ethics approval and consent to participants}

Not applicable because no primary data were collected.

\section{Consent for publication}

Not applicable.

\section{Competing interests}

The authors declared that they have no competing interests.

\section{References}

1. WHO and UNICEF Joint Statement. Home visits for a newborn child (a strategy to improve survival, 2009).

2. Oza, S., Cousens, S. \& Lawn, J. Estimation of daily risk of neonatal death, including the day of birth, in 186 countries in 2013: A vital-registration and modeling-based study. Lancet Glob Health, 2, e635-44 (2014).

3. Lawn, J. et al. Progress, priorities, and potential beyond survival., 384, 189-205 (2014).

4. UN Inter-agency Group for Child Mortality Estimation. Levels \& trends in child mortality: report 2019. New York: UNICEF; 2019. https://www.unicef. org/media/60561/file/UN-IGME-child-mortality-report-2019.pdf. Accessed 14 Oct 2019

5. Beck, S. et al. The worldwide incidence of preterm birth: a systematic review of maternal mortality and morbidity. Bull World Health Organ, 88 (1), $31-38$ (2010).

6. Gomez, H. M., Sanabria, E. R. \& Marquette, C. M. The Mother Kangaroo Programme. International Child Health, 3 (1), $55-67$ (1992).

7. Muchie et al. Epidemiology of preterm birth in Ethiopia: systematic review and meta-analysis: BMC Pregnancy and Childbirth (2020) 20:574

8. Endalamaw et al. Low birth weight and its associated factors in Ethiopia: a systematic review and meta-analysis. Italian Journal of Pediatrics, $\mathbf{4 4 ,} 141$ (2018).

9. Lee, A. C. C., Blencowe, H. \& Lawn, J. E. Small babies, big numbers: global estimates of preterm birth. The Lancet Global Health, 7 (no. 1), 2-3 (2019).

10. World Health Organization. Kangaroo Mother Care: a Practical Guide (WHO, Geneva, Switzerland, 2003).

11. World Health Organization. Guideline: protecting, promoting, and supporting breastfeeding in facilities providing maternity and newborn services. World Health Organization; 2017. Available from: HTTPS:// apps.who.int/iris /bitstream /handle /10665 /259386 /9789241550086-eng. pdf. Accessed June 8, 2021.

12. Baley, J. Skin-to-skin care for the term and preterm infants in the neonatal ICU., 136 (3), 596-599 https://doi.org/10.1542/ (2015).

13. Feldman-Winter, L. et al. Safe sleep and skin-to-skin care in the neonatal period for healthy term newborns.Pediatrics. 2016.

14. Abdulghani, N., Edvardsson, K., Amir, L. H. \& van Wouwe, J. P. Worldwide prevalence of mother-infant skin-to-skin contact after vaginal birth: a systematic review. PLoS One, 13 (10), e0205696 (2018). 10.1371/ journal.pone.0205696

15. Broughton, E., Gomez, I. \& Vindell, N. S. C. The cost-savings of implementing kangaroo mother care in Nicaragua 2013.

16. Bigelow, A., Power, M., MacLellan-Peters, J., Alex, M. \& McDonald, C. Effect of mother/infant skin-to-skin contact on postpartum depressive symptoms and maternal physiological stress 2012.J Obstet Gynecol Neonatal Nurs41:369-382

17. Conde-Agudelo, A. D. R. J. Kangaroo mother care to reduce mortality in low birth weight infants.Cochrane Database Syst Review. 2014;22(4)

18. A-M, B. In: WRHL G, editor. Kangaroo mother care to reduce morbidity and mortality in low-birth-weight infants; 2011

19. Vesel, L. et al. Kangaroo mother care: a multi-country analysis of health system bottlenecks and potential solutions.BMC Pregnancy Childbirth. 2015;15 
20. Bhutta, Z. A. et al. Can available interventions end preventable deaths in mothers, newborn babies, and stillbirths, and at what cost?, 384, 347-370 (2014).

21. Lassi, Z. S., Middleton, P. F., Crowther, C. \& Bhutta, Z. A. Interventions to improve neonatal health and later survival: an overview of systematic reviews.EBio Medicine. 2015; 2 (8)

22. World Health Organization. WHO recommendations on interventions to improve preterm birth outcomes (World Health Organization, Geneva, 2015).

23. Boundy, E., Dastjerdi, R., Spiegelman, D. \& Wafaie, W. Kangaroo Mother Care, and neonatal outcomes: a meta-analysis.Pediatrics. 2016.

24. Karimi, F. Z. et al. The effect of mother-infant skin to skin contact on success and duration of first breastfeeding: A systematic review and metaanalysis:Taiwanese Journal of Obstetrics \& Gynecology58 (2019)

25. Mekonnen et al. The effects of kangaroo mother care on the time to breastfeeding initiation among preterm and LBW infants: a meta-analysis of published studies. International Breastfeeding Journal, 14, 12 (2019).

26. Karimi et al. The effect of mother-infant skin-to-skin contact immediately after birth on exclusive breastfeeding: a systematic review and meta-analysis. $J$ Turk Ger Gynecol Assoc, 21, 46-56 (2020).

27. Ghojazadeh, M. et al. Effect of kangaroo mother care on successful breastfeeding: a systematic review and meta-analysis of randomized controlled trials. RevRecent Clinical Trials. 2019; 14:31_40.

28. VaivadaT, Gaffey, M. F. \& Bhutta, Z. A. Promoting early child development with interventions in health and nutrition: a. systematic review.Pediatrics, 140, e20164308 (2017).

29. Sharma, D., Farahbakhsh, N., Sharma, S., Sharma, P. \& Sharma, A. Role of kangaroo mother care in growth and breastfeeding rates in very low birth weight neonates: a systematic review. J Maternal-Fetal Neonatal Med, 32, 12942 (2019).

30. Cong et al. Skin-to-skin contact to improve premature mothers' anxiety and stress state: A meta-analysis: maternal and child nutrition, Willey 2021 reviewed article

31. Akbari, E. et.al Kangaroo mother care and infant bio-psychosocial outcomes in the first year: A meta-analysis: Elsevier; a journal of. Early Hum. Dev, 122 ( 22 (2018). )

32. Boundy, E. O. et al. Kangaroo Mother Care, and Neonatal Outcomes: A Meta-analysis. Pediatrics, 137 (1), e20152238 (2016).

33. Jafari, M., Farajzadeh, F., Asgharlu, Z., Derakhshani, N. \& Asl, Y. P. Effect of Kangaroo Mother Care on hospital management indicators: A systematic review and meta-analysis of randomized controlled trials. J Edu Health Promot, 8, 96 (2019).

34. Macaraya, J. R. G., Padua, A. P. \& Dans, L. F. Skin to skin contact as analgesia for acute procedural pain in neonates:meta-analysis:Philipins Journal of Pediatricsvol.64.no.12016

35. Shrivastava, S. R., Shrivastava, P. S. \& Ramasamy, J. 2013. Utility of kangaroo mother care in preterm and low birth weight infants. S. Afr. Fam. Pract. 55 (4), 340-344. https:// doi.org/10.1080/20786204.2013.10874373, 2013.

36. Vohra, A. S., Shah, B. H. \& Mehariya, K. M. Effect of kangaroo mother care on feeding, morbidity, and neurodevelopment of low birth weight neonates. Int. J. Contemp. Med. Res, 4, 1029-1032 (2017).

37. Sharma, D., Murki, S. \& Oleti, T. P. Study comparing. Kangaroo Ward Care" with" Intermediate Intensive Care "for improving the growth outcome and costeffectiveness: randomized control trial. J Matern Fetal Neonatal Med. 2018;31:2986_93

38. Acharya, N., Singh, R. R., Bhatta, N. K. \& Poulde, P. Randomized control trial of kangaroo mother care in low birth weight babies at a tertiary level hospital. J Nepal Paediatr Soc. 2014;34:18_23

39. Lumbanraja, S. N. Influence of maternal factors on the successful outcome of kangaroo mother care in low birth-weight infants: a randomized controlled trial. JNeonatal PerinatalMed.2016;

40. Mwendwa, A. C. \& Musoke, R. N. Wamalwa DC.Impactofpartialkan-karoo mother care on growth rates and duration of hospital stay of low birth weight infants at the Kenyatta National Hospital. Nairobi.EastAfrMedJ, 89, 538 (2012).

41. Kumbhojkar, S. \& MokaseY, Sarawade, S. Kangaroo mother care: an alternative to the conventional method of care for low birth weight babies.IntJHealth SciRes.2016;6:36_42

42. Ministry of Health. (2015). Ethiopian National Health Care Quality Strategy 2016-2020.

43. Ministry of Health. (2015). Health Sector Transformation Plan (HSTP).www. Research gate.net /file. PostFileLoader. html?id = 5 6efcc94cbd5c2c1930 fae21\&asse tKey $=$ AS\%3A342023027609601\%401458556052424

44. Ministry of Health. (2015). Newborn and Child Survival Strategy Document Brief Summary 2015/16-2019/20.

45. Hug, L., Alexander, M., You, D. \& Alkema, L. National, regional, and global levels and trends in neonatal mortality between 1990 and 2017 , with scenariobased projections to 2030: a systematic analysis. Lancet Glob Health. 2019;7(6)

46. .Ethiopian Public Health Institute (EPHI)[Ethiopia] and ICF. Ethiopia mini demographic and health survey 2019: key indicators.

47. Penfold, S. et al. A large cross-sectional community-based study of newborn care practices in Southern Tanzania.PLoS One. 2010;5(12)

48. Abdulghani, N., Edvardsson, K., Amir, L. H. \& van Wouwe, J. P. Worldwide prevalence of mother-infant skin-to-skin contact after vaginal birth: a systematic review.PLoS One. 2018

49. Mose et al. Skin-to-Skin Care Practice and Its Associated Factors among Postpartum Mothers in Gurage Zone, Southern Ethiopia: A Cross-Sectional Study (Pediatric Health, Medicine and Therapeutics, 2021).

50. Alelign, Z. Assessment of knowledge, attitude, practice and associated factors towards kangaroo mother care among postnatal mothers paired with their babies at Addis Abeba Public hospitals, 2019: a cross-sectional study: Addis Ababa university institutional repository (unpublished

Page $10 / 19$ 
study);URl:http://etd.aau.edu.et/handle /123456789/2145

51. Getinet et.al. Knowledge, Attitude, Practice and Associated Factors of Kangaroo Mother Care for Neonatal Survival Among Care Takers of Preterm and Low Birth Weight Infants in Health Care Settings, Hawassa, Southern Ethiopia (Journal of Health, Medicine and Nursing, 2019).

52. Roba et al. Knowledge, Attitude and Practice of Kangaroo Mother Care by Postnatal Mothers who Gave Birth to Preterm and Low Birth Weight Babies in Public Hospitals, Eastern Ethiopia: J Neonatal Biol 2017

53. Jamie, A. H. Knowledge, attitude and practice of kangaroo mother care among postnatal mothers in a tertiary care center of Harari region, Harar, Ethiopia. Public Health of Indonesia, 6 (4), 116-122 (2020).

54. Dawit, A. Assessment of Exclusive Breast Feeding Practice and Factors affecting it Among Mothers who Provided Kangaroo Mother Care to Their Preterm Infants In Black Lion Hospital, Addis Ababa, Ethiopia,2015: Addis Ababa university national academic digital repository Ethiopia (unpublished study);URI:adre.etheren.edu.et aau.edu.et

55. Demissie et al. Neonatal hypothermia and associated factors among neonates admitted to neonatal intensive care unit of public hospitals in Addis Ababa, Ethiopia: BMC Pediatrics(2018) 18:263

56. Lakew, W. \& Worku, B. Follow-Up Profile and Outcome of Preterm Managed with Kangaroo Mother Care: Open Journal of Pediatrics, 2014, 4, 143-147

57. Dabre, N. et.al.Maternal Health Service Uptake Is Associated with a Higher Skin-to-Skin Care Practice in Ethiopia: Result from a National Survey: BioMed Research International Volume 2020,Article ID8841349,10pages

58. Haftay Gebremedhin, H. D. Hidru,Berihu Gidey,Medhin Mehari,Meresa Berwo and Muzayene Tilahun. Kangaroo mother care practice and its associated factors among postnatal mothers who gave birth in public general hospitals of Eastern and Central zone, Tigray, North Ethiopia 2019:under review (unpublished study)

59. Weldearegay, H. G. et al. 2019. Quality of Kangaroo Mother Care services in Ethiopia: Implications for policy and practice.PLoS ONE14(11)

60. Ayele, M. W. et al. Proportion of mothers practicing kangaroo mother care at home and factors influencing the practices following hospital discharge, South Wollo, Ethiopia:. Journal of Neonatal Nursing, 27 ( 118-122 (2021). )

61. Ebrahim, Y. et.al. Utilization of Kangaroo Mother Care (KMC) and Influencing Factors Among Mothers and Care Takers of Preterm/Low Birth Weight Babies in Yirgalem Town, Southern, Ethiopia: Diversity and Equality in Health and Care (2018) 15(2):87-92

62. Gebre et.al. Newborn-Care Practices and Health-Seeking Behavior in Rural Eastern Ethiopia: A Community-Based Study. Journal of Tropical Pediatrics, 64, 90-96 (2018).

63. Bedaso et al. Assessment of skin-to-skin contact during the postpartum stay and its determinant factors among mothers at public health institutions in Ethiopia. : BMC Res Notes, 12, 136 (2019). )

64. Emishaw et.al. Mothers Practice and Associated Factors on Kangaroo Mother Care, in Mekelle City Hospitals Tigray, North Ethiopia: A Cross-Sectional Survey: Research \& Reviews:A Journal of Immunology

65. Moher, D., Liberati, A., Tetzlaff, J., Altman, D. G. \& The PRISMA Group. The Preferred Reporting Items for Systematic Reviews and Meta-Analyses: The PRISMA Statement. PLoS Med, 6 (7), e1000097 https://doi.org/10.1371/journal.pmed1000097 (2009).

66. Arthur, J. et al. Mary Settle, and Denise Williams. National Survey of Practice (The American Journal of Maternal/Child Nursing · May, Knowledge, Barriers, and Perceptions, 2002).

67. Chiou, S-T., Chen, L-C., Yeh, H., Wu, S-R. \& Chien, L-Y. Early skin-to-skin contact, rooming-in, and breastfeeding: A comparison of the 2004 and 2011 National Surveys in Taiwan. Birth: Issues in Perinatal Care. 2014; 41(1):33-8. https://doi.org/10.1111/birt.12090 PMID: 24654635

68. Andersson, C. B., Flems, C. \& Kesmodel, U. S. The Danish National Quality Database for Births. Clinical Epidemiology. 2016; 8:595-9. https://doi.org/10.2147/CLEP.S99492 PMID: 27822105

69. Chalmers, B. et al. Cesarean and vaginal birth in Canadian women: a comparison of experiences. Birth, 37 (1), 44-49 https://doi.org/10.1111/j (2010).

\section{Figures}



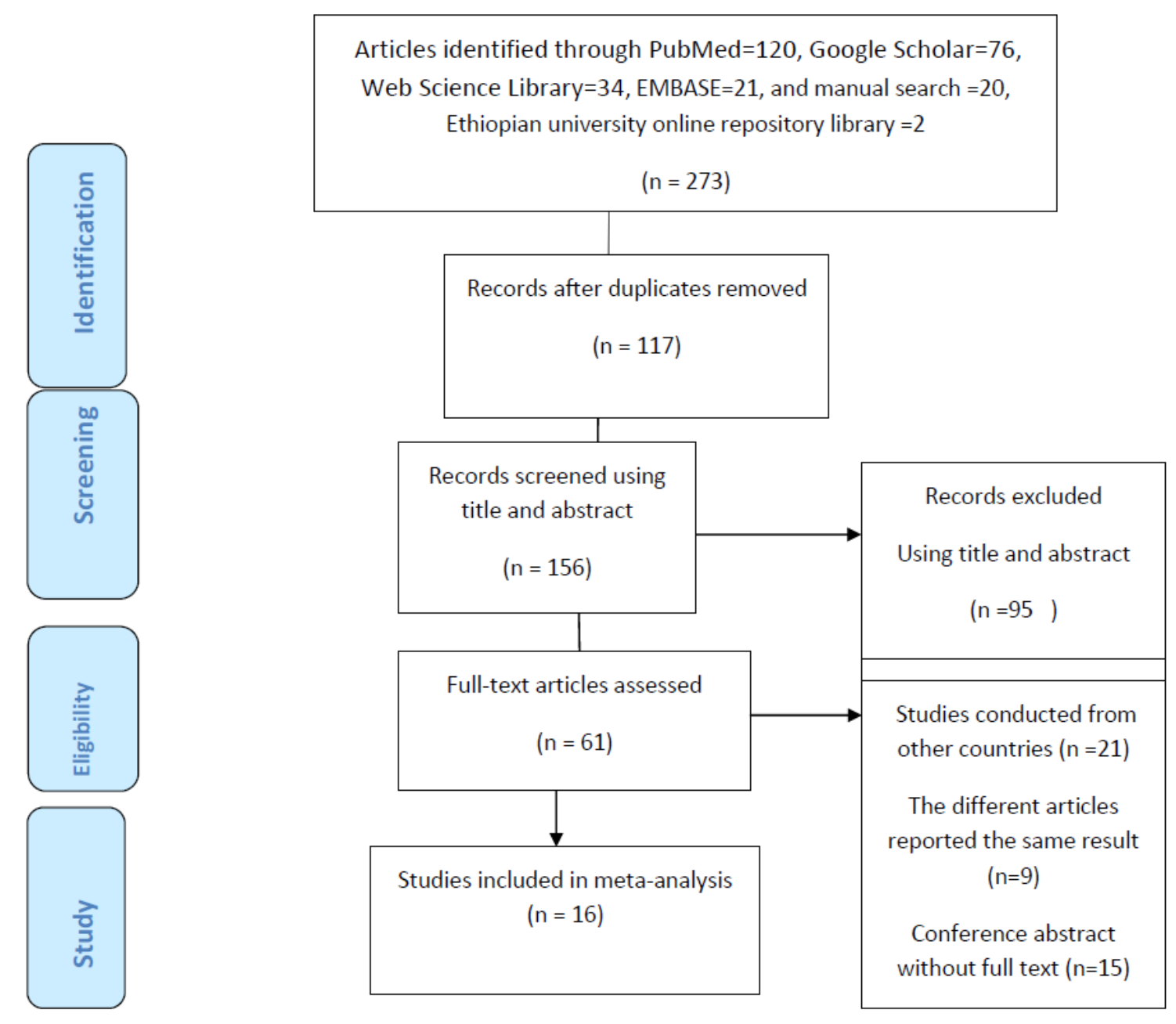

Figure 1

PRISMA diagram showing studies used for Systematic Review and Meta-analysis of the knowledge, attitude, and practice of kangaroo mother care in Ethiopia 


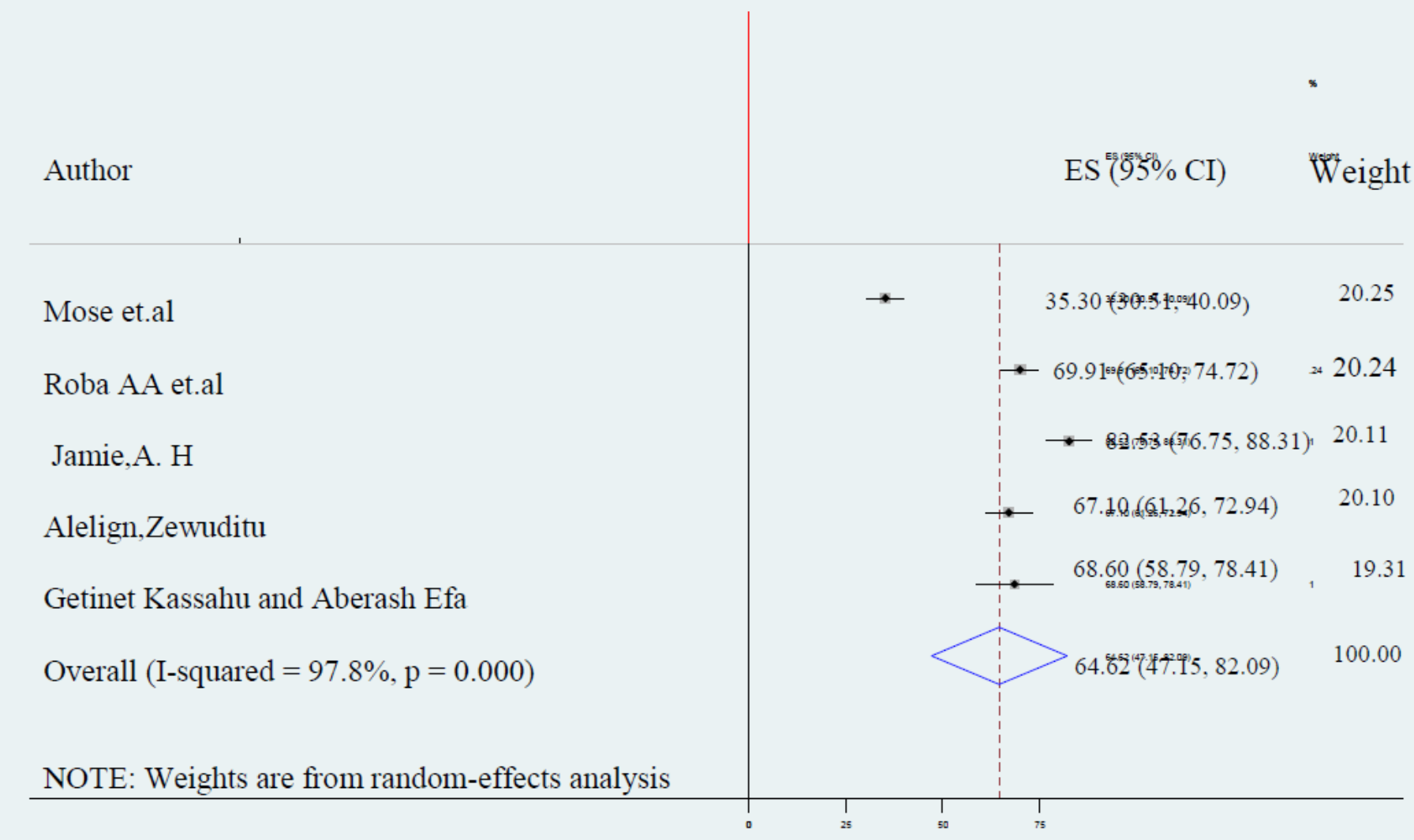

Figure 2

Forest plot for the pooled level of good knowledge of kangaroo mother care among postnatal women in Ethiopia 


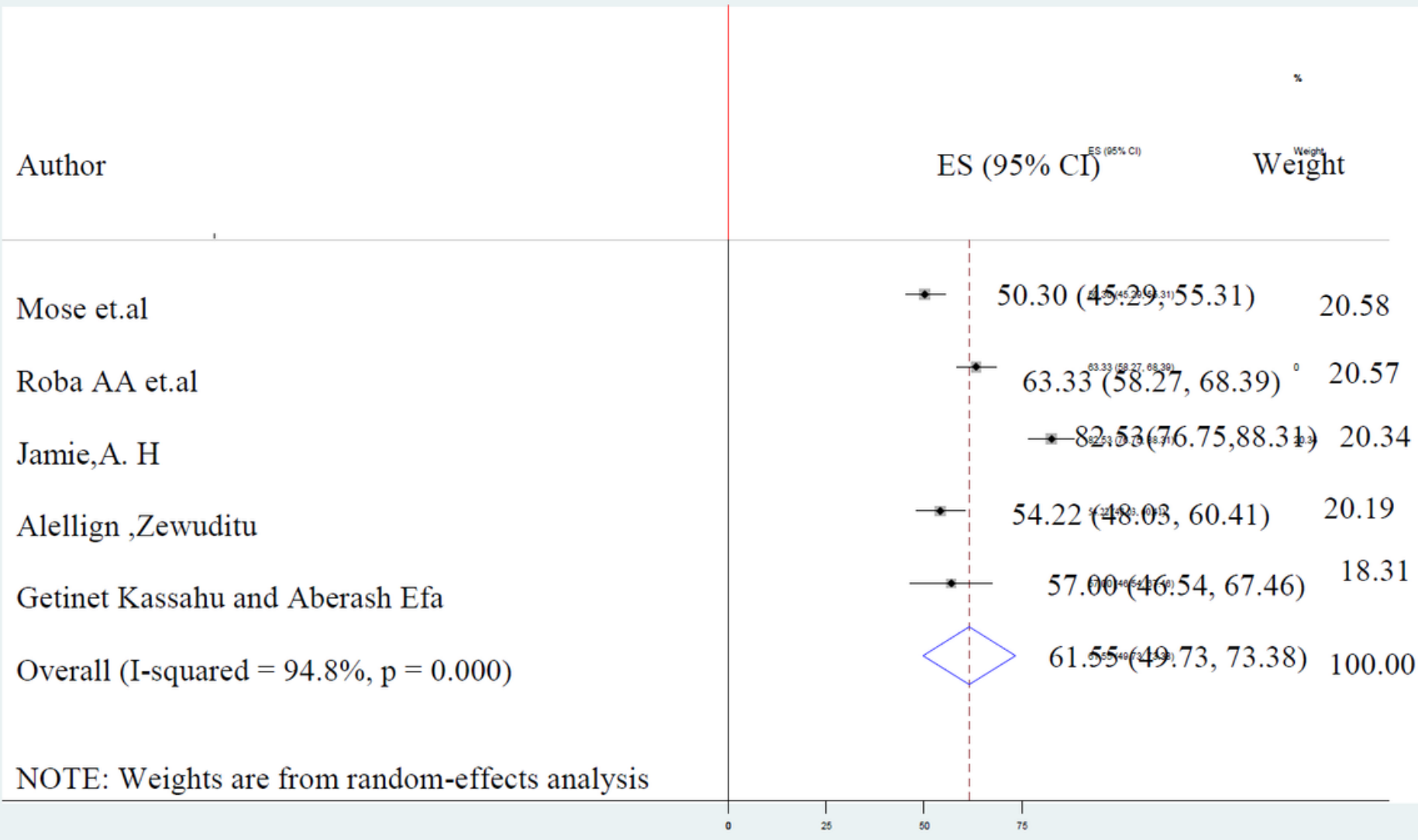

Figure 3

Forest plot for the pooled level of positive attitude towards kangaroo mother care among postnatal women in Ethiopia 


Author
Mose et.al
Gebre et.al

\section{Figure 4}

Forest plot for the pooled level of poor practice towards kangaroo mother care among postnatal women in Ethiopia

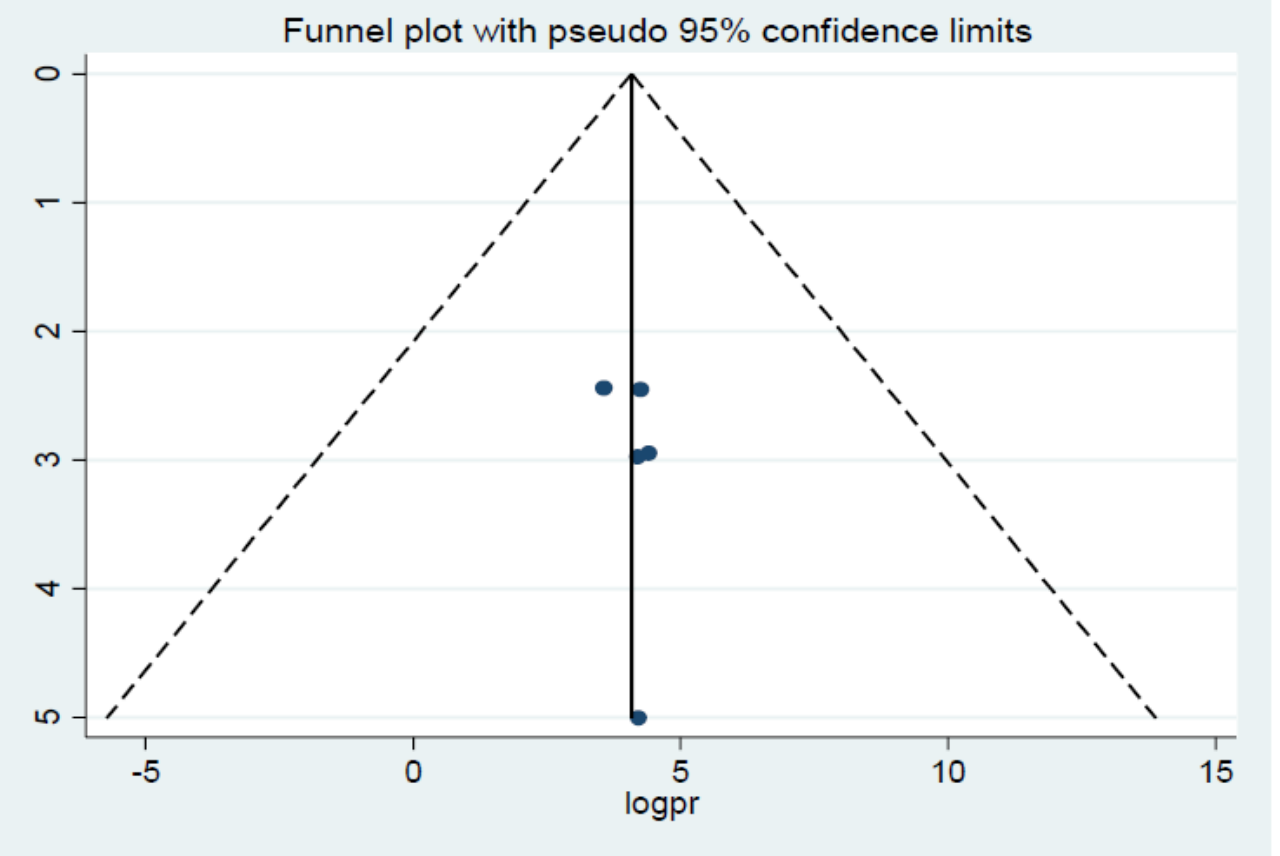

Figure 5

Funnel plots for publication bias of level of good knowledge towards kangaroo mother care among postnatal women in Ethiopia 


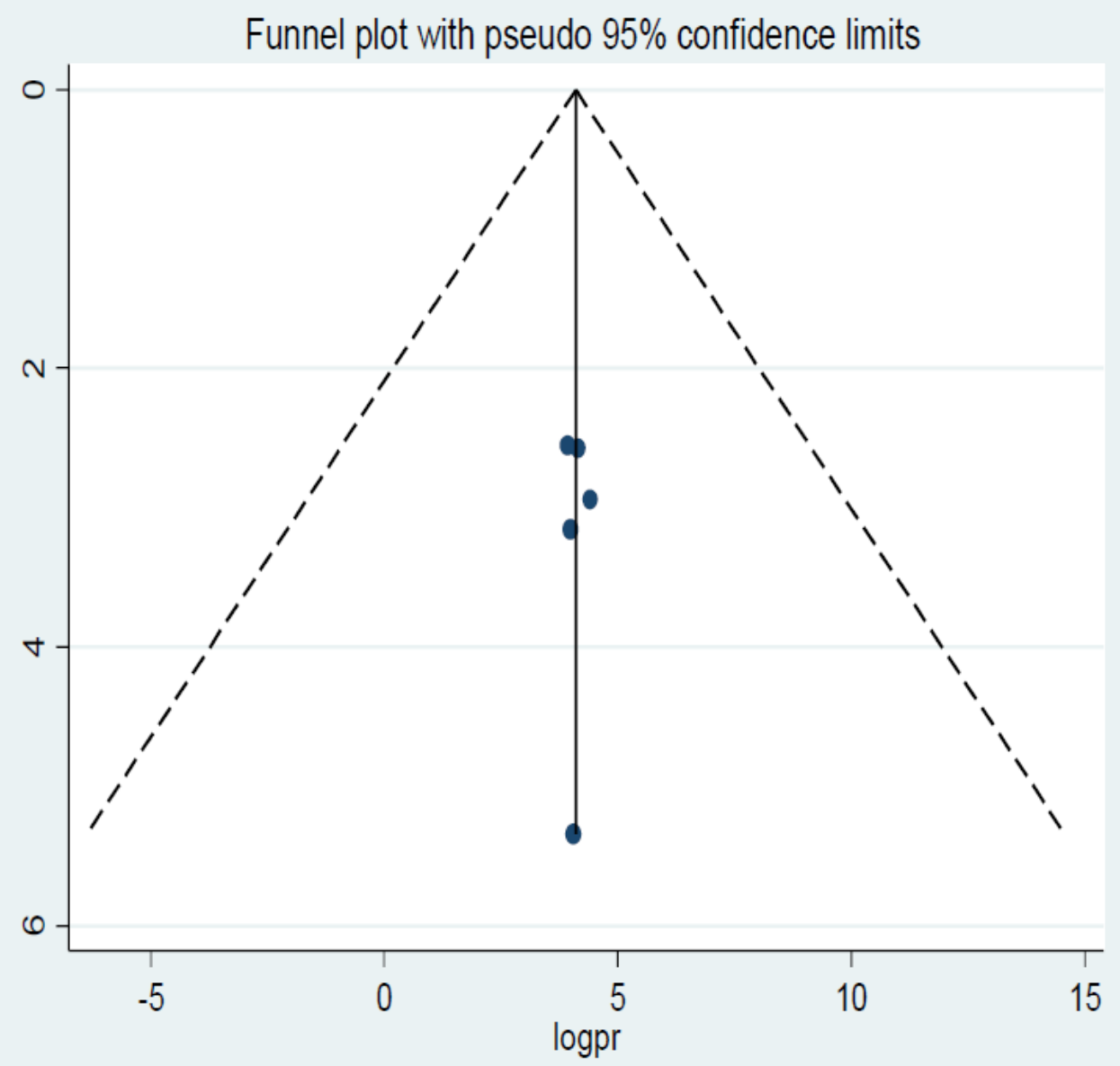

Figure 6

Funnel plots for publication bias of level of positive attitude towards kangaroo mother care among postnatal women in Ethiopia 


\section{Funnel plot with pseudo $95 \%$ confidence limits}

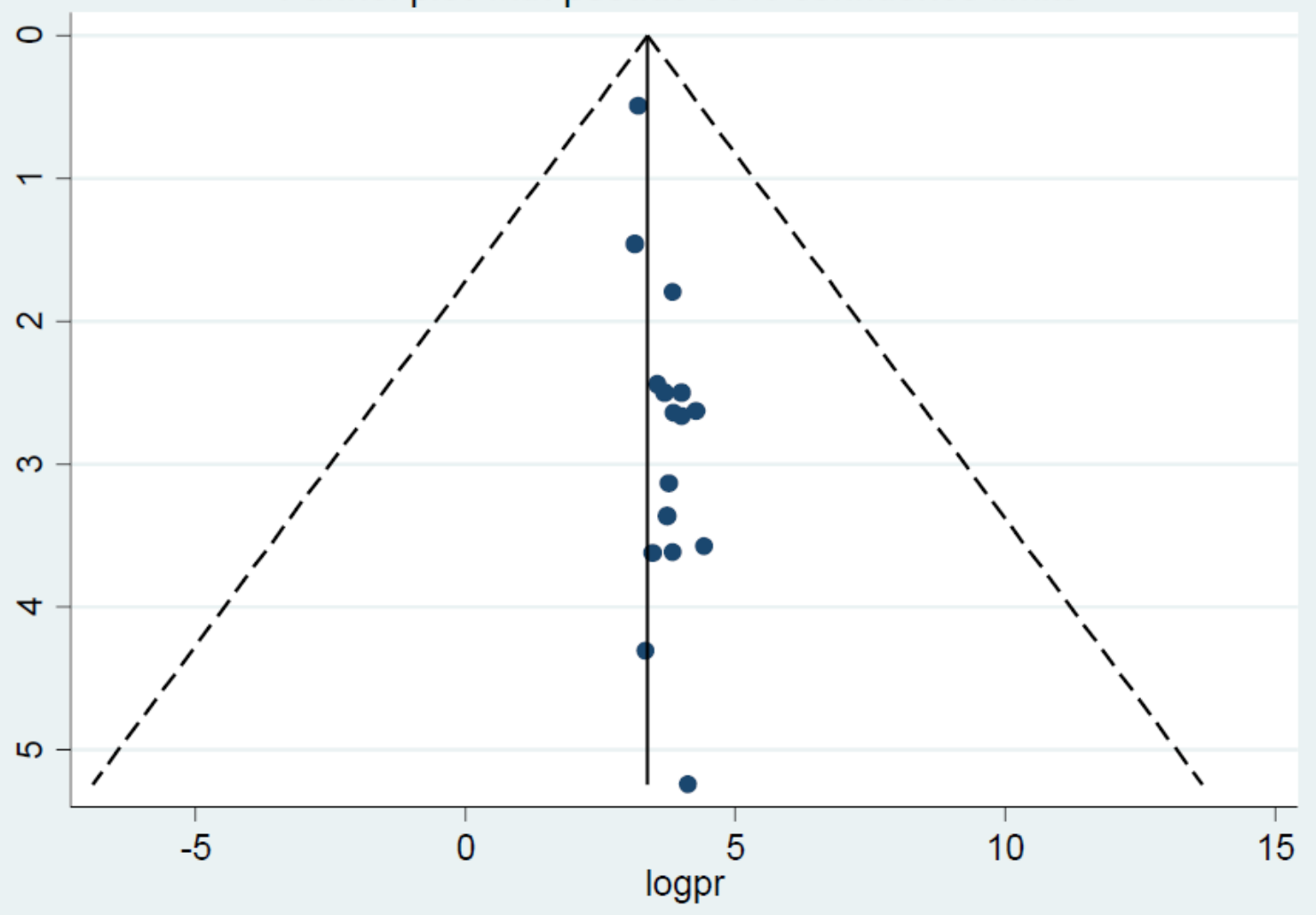

Figure 7

Funnel plots for publication bias of level of poor practice towards kangaroo mother care among postnatal women in Ethiopia 
Filled funnel plot with pseudo $95 \%$ confidence limits

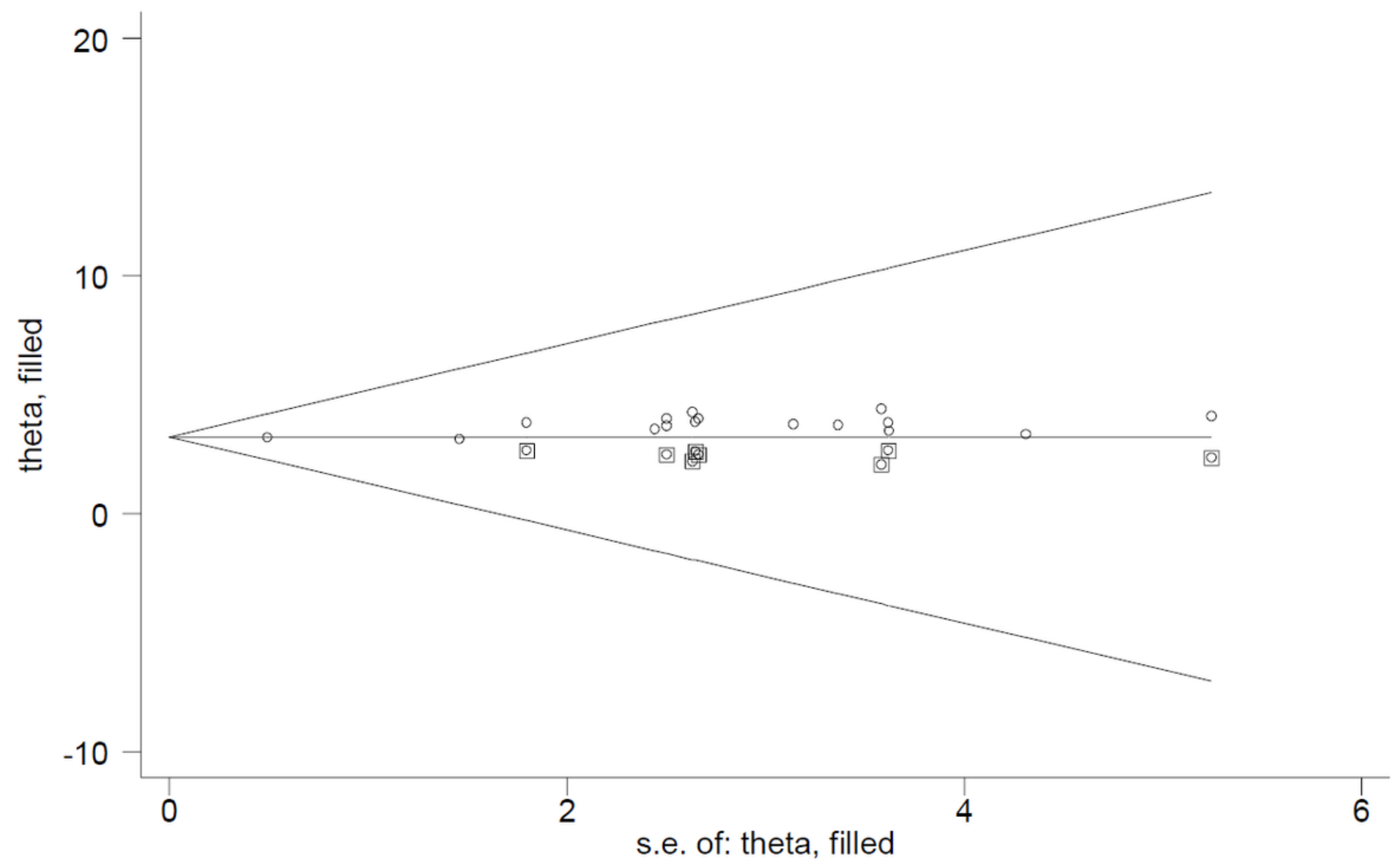

Figure 8

Funnel plot of trim and analysis for the level of poor practice of kangaroo mother care in Ethiopia. 


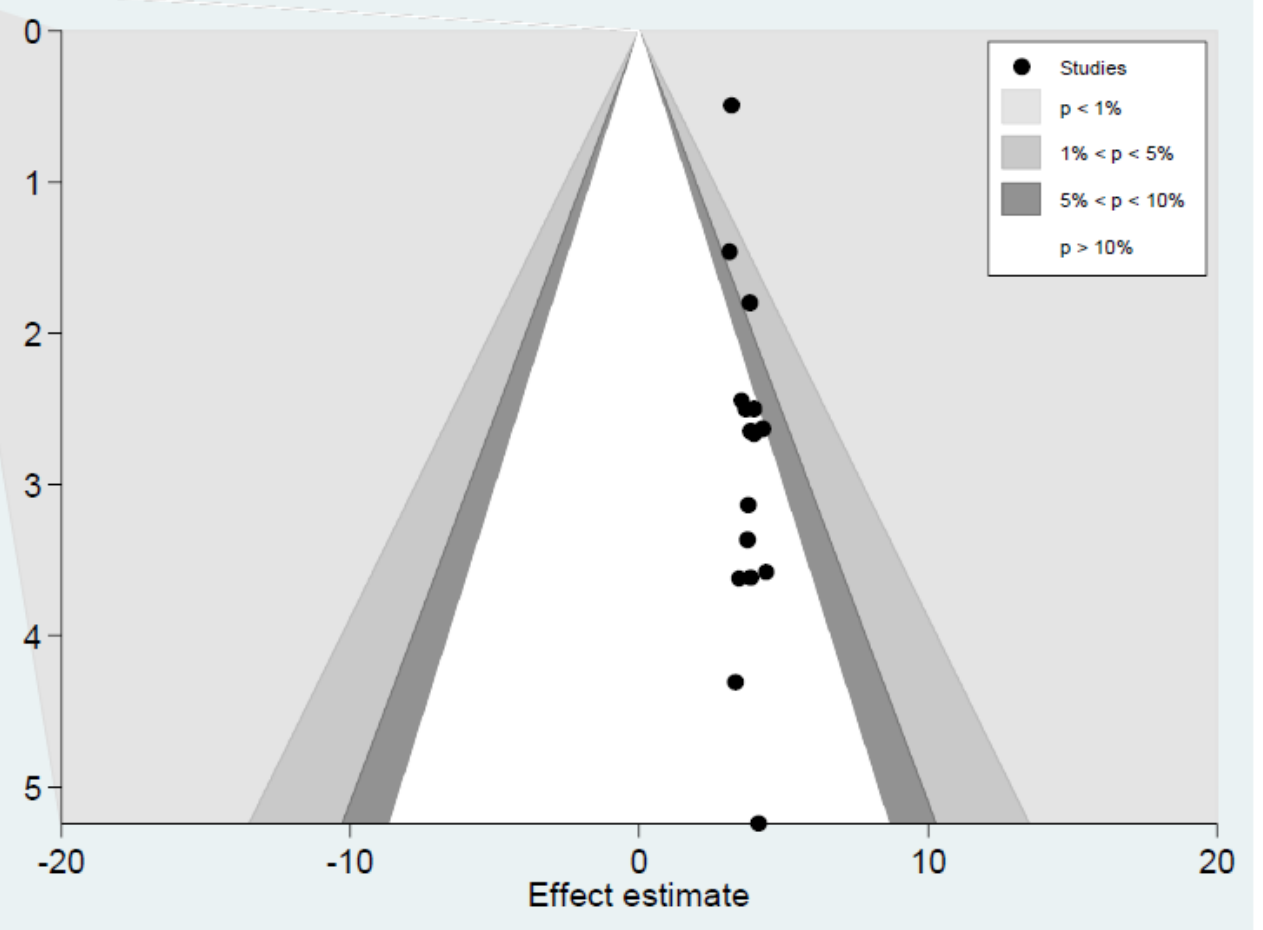

Figure 9

Counter-enhanced funnel plot for checking the cause of publication bias of poor level of kangaroo mother care practice in Ethiopia. 